\title{
Perception of fattening foods in Italian children and adolescents
}

\author{
Stefania Toselli, Patricia Brasili, Rocco Di Michele and Federico Spiga*
}

\begin{abstract}
The present study aimed to analyze, in Italian children and adolescents, the beliefs about which foods are fattening, the appreciation of fattening foods, and the perception of some socio-cultural attributes of them. 244 children (F: 125, M: 119, aged 8-11) and 305 adolescents (F: 153; M: 152, aged 11-14) from Bologna, Northern Italy, were asked to indicate five fattening foods. For each of the indicated foods, a yes-no answer was required to the question: "is this food special for you?", and to six questions concerning socio-cultural attributes of the food, which were modelled using a latent variable with two classes named "traditional" and "modern". Pearson's chi square tests revealed, both in boys and girls, significant associations between the age class and the foods indicated as fattening: lean meat, condiments, non-sweet fruit and vegetables were more often indicated as fattening by children than by adolescents. Overall, boys showed higher appreciation and perception of fashionability of fattening foods. Girls appreciated less bread and pasta, and indicated more often than boys these foods as fattening. The different food perception of between age classes and sexes can be respectively explained by a better dietary awareness of adolescents, and by girls worrying about their look more than boys.
\end{abstract}

Keywords: Body-mass index; Italy; Nutritional habits; Children; Adolescents; Obesity; Overweight; Fattening food

\section{Background}

Childhood overweight and obesity are relevant public health problems, rapidly growing in industrialized countries during the last decades. In Italy, obesity has emerged since the 1990s (International Obesity Taskforce 2012) and continues to increase dramatically especially among children and adolescents. The prevalence of childhood overweight and obesity is the highest in the South of Italy (overweight: 27.1\%; obesity: 13.5\%) and the lowest in the North (overweight: 22.9\%; obesity: 5.9\%) (Inran 2009). Moreover, these percentages vary according to the regions, with overweight ranging from $14.9 \%$ to $40.6 \%$, and obesity ranging from $2.4 \%$ to $19.5 \%$ (Toselli et al. 2014, Toselli et al. 2012). The prevalence of obesity tends to decrease in the adolescence, especially among girls, as the care of body image becomes usually important at this age. Toselli et al. (2010), in a sample of adolescents from Bologna (northern Italy), reported obesity rates of 5.5\% (at age 12) and $3.9 \%$ (at age 13) for boys, and of 3.2\% (at age 12) and $1.1 \%$ (at age 13) for girls. A lower percentage of

\footnotetext{
* Correspondence: federico.spiga2@unibo.it

Department of Biomedical and Neuromotor Sciences, University of Bologna, Bologna, Italy
}

obesity amongst adolescent girls when compared with age-matched boys was also observed in other European countries (World Health Organization 2009), and in the central-northern Italian population (Cacciari et al. 2006).

The transition from childhood to adolescence is a period in which the weight status can change due to nutritional behaviours and lifestyle habits such as practicing or not physical activity (Haerens et al. 2010). In children, nutritional patterns are mostly affected by school meals programs and by the control of parents (Demory-Luce et al. 2004), whereas adolescents usually self-select the food they like to eat, often resulting in a change of the previous nutritional habits and of food preferences. For example, Lytle et al. (2000) showed that, when students finish primary school, fruit consumption falls by $41 \%$, while vegetables consumption falls by $25 \%$. In another study, (Demory-Luce et al. 2004) and colleagues (Toselli et al. 2010) observed that, when compared to children, young adults decrease the consumption of meats, fruit, desserts, candy and milk, and increase the consumption of sweetened beverages, poultry, salty, snacks, seafood, cheese, beef and condiments. 
Analysing how food consumption patterns develop during childhood is an important tool to understand the pathogenesis of weight disorders. Previous studies have considered food preferences (Cook and Frank 2007, Harris 2008, Cornwell and McAlister 2011), the role of branding (Halford et al. 2007), and familiarity in dietary development (Aldridge et al. 2009, Boukthir et al. 2011). According to Ulijaszek (2007), food intake is driven psychologically by innate and cognitive factors related to the food environment. The connection between the brain and gut affects the perceived qualities of foods through specific sensations such as smell, expectation, association with pleasure or disgust. Therefore, knowing that a food is unhealthy may not necessarily result in a reduced consumption of it. On the contrary, the potential fattening effect of a food may be a factor that leads to limit the consumption of that food when one's aim is to avoid overweight and obesity. In the Italian case, identifying the popular perception of fattening foods in children and adolescents can contribute to understand the reasons for the between-sex differences of overweight and obesity observed in these age ranges. To this aim, this study analyses which foods are believed to be fattening, the extent to which these food are appreciated, and how some socio-cultural attributes of them are perceived.

\section{Results and discussion}

Table 1 shows the weight status/age class contingency tables in boys and girls. Overweight was more prevalent among boys (about $22 \%$ for both children and adolescents), than among girls (about 15\% and 12\% in children and adolescents, respectively). In both sexes, there were no significantly different weight status distributions between children and adolescents $(p>0.05)$. Due to the limited number of underweight and obese participants, these categories were respectively included in the normal weight and overweight categories for the subsequent analyses.

\section{Table 1 Weight status/age class contingency tables}

\begin{tabular}{lcc}
\hline Boys & Children & Adolescents \\
\hline Underweight & 0 & 2 \\
Normalweight & 89 & 113 \\
Overweight & 26 & 33 \\
Obese & 4 & 4 \\
\hline Girls & Children & Adolescents \\
& 3 & 4 \\
Underweight & 100 & 130 \\
Normalweight & 19 & 18 \\
Overweight & 3 & 1 \\
Obese & &
\end{tabular}

The foods indicated as fattening showed, both in boys and girls, significantly different distributions $(\mathrm{p}<0.05)$ between children and adolescents (Table 2). In particular, four food categories were the most responsible for the association between the two variables: lean meat, representing 6 to $7 \%$ of all fattening foods indicated by children, and 3 to $4 \%$ of fattening foods indicated by adolescents; oils and condiments, indicated more often by adolescents (boys: $7.1 \%$; girls: 10.9\%) than by children (about $4 \%$ in both sexes); non-sweet fruit/cereals and vegetables, both food types very rarely indicated as fattening by adolescents ( 0 to $0.5 \%$ ), but sometimes indicated by children (each category 1.5 to $2.5 \%$ ). It is worth noting that, overall, bread and pasta are indicates as fattening much more often by girls than by boys (Table 2).

No association $(p>0.05)$ was found between weight status and food category, both in boys and girl. In other words, normal weight and overweight participants did not show differences regarding the foods believed to be fattening (Table 2).

Table 3 shows the percentage of "yes" responses to the question on fattening food appreciation and to six questions on socio-cultural attributes of foods. All the seven variables were associated to the food category in both boys and girls (all $p>0.05$ ). In other words, for all the questions and in both sexes, the percentage of "yes" responses was different among at least some food categories.

The appreciation of fattening foods was, overall, higher in boys (65.8\% of "yes" responses to the question "is this food special for you?") than in girls (59.9\%). Among the foods indicated as fattening in $1 \%$ of total cases or more, the most appreciated foods were pizza (percentage of "yes" answers to the question "is this food special for you?": $85.5 \%$ for boys and $74.3 \%$ for girls) and fried potatoes $(80.2 \%$ for boys and $68.6 \%$ for girls), whereas oils and condiments was the less appreciated foods (32.9\% for boys and $41.4 \%$ for girls). It's worth noting that boys appreciated much more than girls bread and pasta $(80.0 \%$ vs. $55.5 \%)$ and fat meat (68.9\% vs. $44.0 \%)$.

Regarding the socio-cultural attributes (Table 3), some of the food categories were considered, more than others, to be natural and typical of the local (regional) area and in some case of the countryside. These foods includes bread and pasta, cold cuts, dairy products, eggs, lean meat, oils and condiments, sweet fruit, and vegetables. Other foods like juices and drinks, fried potatoes, and fat meat were, on the contrary, more considered as being new, fashionable, and typical of an urban environment. Some differences between sexes were noticed regarding how the socio-cultural characteristics of fattening foods are perceived (Table 3). Of particular relevance is that girls (when compared to boys) consider some foods less fashionable (like pizza, pasta/bread, filled cakes/sweets, fried potatoes, biscuits and ice creams), and 
Table 2 Percentage distributions of categories for foods indicated as fattening

\begin{tabular}{|c|c|c|c|c|c|}
\hline \multicolumn{6}{|l|}{ Boys } \\
\hline & Overall & Children & Adolescents & Normalweight & Overweight \\
\hline Chocolate and snacks & 23.2 & 20.5 & 25.3 & 22.5 & 25.1 \\
\hline Biscuits and ice creams & 18.5 & 19.2 & 18.0 & 18.4 & 18.8 \\
\hline Fat Meat & 10.9 & 13.3 & 9.1 & 11.5 & 9.3 \\
\hline Filled cakes and sweets & 8.0 & 6.7 & 8.9 & 8.3 & 6.9 \\
\hline Fried potatoes & 7.5 & 6.6 & 8.2 & 8.1 & 5.4 \\
\hline Oils and condiments & 5.6 & 3.7 & 7.1 & 5.1 & 7.2 \\
\hline Lean meet & 5.1 & 7.1 & 3.6 & 5.4 & 4.2 \\
\hline Cold cuts & 4.9 & 4.9 & 4.9 & 5.4 & 3.3 \\
\hline Bread and pasta & 4.4 & 4.4 & 4.5 & 3.8 & 6.3 \\
\hline Pizza & 4.1 & 4.9 & 3.4 & 4.0 & 4.2 \\
\hline Juices and drinks & 2.4 & 2.4 & 2.4 & 2.3 & 2.7 \\
\hline Dairy products & 1.5 & 0.8 & 2.0 & 1.4 & 1.8 \\
\hline Vegetables & 1.3 & 2.4 & 0.5 & 1.3 & 1.5 \\
\hline Non-sweet fruits and cereals & 1.0 & 1.8 & 0.3 & 0.7 & 1.8 \\
\hline Eggs & 0.7 & 0.5 & 0.9 & 0.7 & 0.9 \\
\hline Fried fish & 0.6 & 0.5 & 0.7 & 0.6 & 0.6 \\
\hline Fish & 0.3 & 0.5 & 0.1 & 0.4 & 0.0 \\
\hline Sweet fruit & 0.1 & 0.0 & 0.3 & 0.1 & 0.3 \\
\hline \multicolumn{6}{|l|}{ Girls } \\
\hline & Overall & Children & Adolescents & Normalweight & Overweight \\
\hline Chocolate and snacks & 26.5 & 25.6 & 27.2 & 27.2 & 22.4 \\
\hline Biscuits and ice creams & 16.3 & 17.0 & 15.7 & 15.7 & 19.5 \\
\hline Bread and pasta & 9.2 & 9.8 & 8.8 & 8.2 & 15.1 \\
\hline Oils and condiments & 8.0 & 4.5 & 10.8 & 7.9 & 8.3 \\
\hline Fried potatoes & 7.6 & 6.9 & 8.1 & 7.9 & 5.4 \\
\hline Filled cakes and sweets & 7.0 & 6.7 & 7.2 & 7.4 & 4.4 \\
\hline Fat Meat & 5.4 & 4.8 & 5.9 & 5.6 & 4.4 \\
\hline Cold cuts & 5.3 & 5.3 & 5.4 & 5.2 & 5.9 \\
\hline Lean meet & 4.2 & 6.1 & 2.7 & 4.3 & 3.9 \\
\hline Juices and drinks & 2.5 & 3.0 & 2.1 & 2.3 & 3.9 \\
\hline Pizza & 2.5 & 3.5 & 1.7 & 2.4 & 2.9 \\
\hline Dairy products & 1.8 & 1.6 & 2.0 & 1.9 & 1.5 \\
\hline Non-sweet fruits and cereals & 1.0 & 1.4 & 0.7 & 1.1 & 0.5 \\
\hline Vegetables & 0.9 & 1.6 & 0.4 & 1.0 & 0.5 \\
\hline Sweet fruit & 0.6 & 1.1 & 0.3 & 0.7 & 0.5 \\
\hline Eggs & 0.5 & 0.6 & 0.4 & 0.4 & 1.0 \\
\hline Fish & 0.4 & 0.3 & 0.4 & 0.4 & 0.0 \\
\hline Fried fish & 0.3 & 0.2 & 0.4 & 0.3 & 0.0 \\
\hline
\end{tabular}

some foods more fashionable (in particular cold cuts and juices/drinks).

The present study assessed the beliefs of Italian children and adolescents about which foods are fattening, and evaluated the extent to which fattening foods are appreciated and how their socio-cultural attributes are perceived. Understanding how dietary habits develop in young people is important for planning effective nutritional intervention strategies. In fact, it is believed that nutritional habits tracks into adulthood from childhood 
Table 3 Percentage of "yes" responses to the question "is this food special for you? " and to questions on socio-cultural attributes of foods

\begin{tabular}{|c|c|c|c|c|c|c|c|}
\hline \multicolumn{8}{|l|}{ Boys } \\
\hline & Special & New & Fashionable & Natural & Local & T city & T countryside \\
\hline Biscuits and ice creams & 65.3 & 18.7 & 44.6 & 28.7 & 11.2 & 35.1 & 11.2 \\
\hline Bread and pasta & 80.0 & 8.3 & 31.7 & 73.3 & 16.7 & 23.3 & 10.0 \\
\hline Chocolate and snacks & 64.3 & 22.6 & 49.0 & 31.5 & 11.1 & 38.2 & 4.5 \\
\hline Cold cuts & 60.6 & 9.1 & 19.7 & 74.2 & 27.3 & 6.1 & 36.4 \\
\hline Dairy products & 55.0 & 10.0 & 25.0 & 85.0 & 30.0 & 20.0 & 35.0 \\
\hline Eggs & 80.0 & 10.0 & 20.0 & 70.0 & 0.0 & 10.0 & 20.0 \\
\hline Fat Meat & 68.9 & 30.4 & 54.1 & 38.5 & 15.5 & 41.2 & 11.5 \\
\hline Filled cakes and sweets & 72.2 & 14.8 & 50.9 & 31.5 & 21.3 & 35.2 & 6.5 \\
\hline Fish & 75.0 & 0.0 & 50.0 & 75.0 & 25.0 & 50.0 & 25.0 \\
\hline Fried fish & 50.0 & 37.5 & 12.5 & 50.0 & 0.0 & 37.5 & 37.5 \\
\hline Fried potatoes & 80.2 & 33.7 & 60.4 & 24.8 & 9.9 & 48.5 & 6.9 \\
\hline Juices and drinks & 56.3 & 34.4 & 46.9 & 18.8 & 15.6 & 37.5 & 9.4 \\
\hline Lean meet & 58.0 & 4.3 & 26.1 & 84.1 & 11.6 & 15.9 & 18.8 \\
\hline Non-sweet fruits and cereals & 69.2 & 23.1 & 30.8 & 69.2 & 15.4 & 23.1 & 30.8 \\
\hline Oils and condiments & 32.9 & 9.2 & 26.3 & 69.7 & 3.9 & 22.4 & 23.7 \\
\hline Pizza & 85.5 & 21.8 & 58.2 & 43.6 & 30.9 & 40.0 & 9.1 \\
\hline Sweet fruit & 100.0 & 0.0 & 0.0 & 100.0 & 0.0 & 0.0 & 0.0 \\
\hline Vegetables & 50.0 & 11.1 & 22.2 & 88.9 & 22.2 & 5.6 & 22.2 \\
\hline OVERALL & 65.8 & 19.8 & 44.1 & 42.7 & 14.2 & 33.2 & 12.0 \\
\hline \multicolumn{8}{|l|}{ Girls } \\
\hline & Special & New & Fashionable & Natural & Local & T city & $\mathrm{T}$ countryside \\
\hline Biscuits and ice creams & 61.1 & 13.7 & 35.8 & 30.5 & 15.0 & 24.8 & 8.0 \\
\hline Bread and pasta & 55.5 & 7.8 & 15.6 & 55.5 & 18.8 & 14.1 & 14.8 \\
\hline Chocolate and snacks & 64.1 & 26.4 & 47.3 & 28.8 & 12.0 & 30.7 & 4.6 \\
\hline Cold cuts & 58.1 & 13.5 & 28.4 & 66.2 & 35.1 & 5.4 & 20.3 \\
\hline Dairy products & 56.0 & 12.0 & 20.0 & 76.0 & 8.0 & 16.0 & 40.0 \\
\hline Eggs & 57.1 & 14.3 & 28.6 & 85.7 & 14.3 & 42.9 & 14.3 \\
\hline Fat Meat & 44.0 & 48.0 & 46.7 & 29.3 & 14.7 & 48.0 & 8.0 \\
\hline Filled cakes and sweets & 67.0 & 24.7 & 37.1 & 32.0 & 16.5 & 30.9 & 9.3 \\
\hline Fish & 20.0 & 0.0 & 0.0 & 80.0 & 40.0 & 20.0 & 40.0 \\
\hline Fried fish & 25.0 & 100.0 & 25.0 & 50.0 & 50.0 & 75.0 & 0.0 \\
\hline Fried potatoes & 68.6 & 34.3 & 50.5 & 27.6 & 11.4 & 41.9 & 4.8 \\
\hline Juices and drinks & 60.0 & 42.9 & 60.0 & 17.1 & 17.1 & 37.1 & 2.9 \\
\hline Lean meet & 67.8 & 11.9 & 30.5 & 76.3 & 22.0 & 8.5 & 13.6 \\
\hline Non-sweet fruits and cereals & 35.7 & 7.1 & 35.7 & 71.4 & 42.9 & 14.3 & 35.7 \\
\hline Oils and condiments & 41.4 & 8.1 & 25.2 & 66.7 & 16.2 & 7.2 & 18.0 \\
\hline Pizza & 74.3 & 11.4 & 37.1 & 40.0 & 34.3 & 22.9 & 11.4 \\
\hline Sweet fruit & 77.8 & 22.2 & 11.1 & 77.8 & 55.6 & 0.0 & 44.4 \\
\hline Vegetables & 69.2 & 23.1 & 15.4 & 100.0 & 7.7 & 15.4 & 0.0 \\
\hline OVERALL & 59.9 & 21.1 & 37.1 & 41.5 & 16.9 & 25.2 & 10.4 \\
\hline
\end{tabular}

T city: Typical of the city; T countryside: Typical of the countryside. 
(Nicklas et al. 1991, Boulton et al. 1995), and establishing healthy eating patterns at a young age can support nutritional habits in the following stages of the life (Kranz et al. 2004). Previous studies investigating this topic assessed the association between food marketing exposure and food choice, suggesting that exposure to television food advertisements and other marketing sources are linked to adolescent food choice and eating behaviours (Bannon and Schwartz 2006, Kelly et al. 2010, Scully et al. 2012). Furthermore, increased television watching has been associated to decreased nutritional knowledge and reasoning (Bannon and Schwartz 2006, Harrison and Marske 2005). An essential novelty of the present investigation is that it is specifically focused on the perception of fattening foods in a youth population. These results, on the whole, show a poorer dietary knowledge of children with respect to adolescents, and a different perception and appreciation of fattening foods in boys with respect to girls.

An association between age class and food category has been detected, suggesting that children and adolescents, when compared each to the others, indicate more or less frequently some specific foods or food categories. An examination of the percentage distributions of food categories (Table 2) reveals that children indicate, in some cases, foods that are not actually fattening, such as vegetables, non-sweet fruit and cereals, or lean meat. Conversely, children tend to rarely consider oils and condiments as fattening, whereas adolescents include more often these foods amongst fattening foods. These results clearly reveal a better dietary knowledge of adolescents, supporting that students have more opportunities of nutritional education as they advance in their scholastic experience, in agreement with what postulated by Yoon et al. (2008).

The present results show a clearly different perception of fattening foods in the two sexes. Overall, boys demonstrate a higher appreciation of fattening foods when compared to girls. This is in agreement with the inverse relationship between children's perceptions of the healthiness of food and their preference of them, described by Noble et al. (2000). Specifically, boys appreciate more than girls the fat meat, fried potatoes, pizza, and especially bread and pasta. Furthermore, bread and pasta constitute $9.2 \%$ of the fattening foods indicated by girls, whereas boys consider such a category as fattening food only in $4.4 \%$ of cases. With high probability, girls are much influenced by popular dietary recommendations about the need to limit carbohydrate intake, which in the Italian diet are usually represented by bread and pasta. In fact, at these ages, girls take care to their figure and look much more than age-matched boys. This is demonstrated, for example, by Argnani et al. (2008), reporting that, in Italy, the ideal body image is larger in boys than in girls at the age of 8 and 9 . Similarly to a previous study (Toselli et al. 2010), we observed a higher proportion of underweight subjects among girls (especially adolescents) than among boys, as well as a lower proportion of obese and overweight. Several authors (Marlett et al. 2002, Kaline et al. 2007, Mellen et al. 2008, Alexy et al. 2010) have reported the health effects of whole grains with respect to heart disease, cancer, gastrointestinal health, diabetes, and weight management studies. Despite in most cases these health effects have only been shown for adults, an elevated whole-grain intake may be desirable already in early life, as dietary habits develop during the early childhood and can track until adulthood (Lake et al. 2006). It was shown, using dietary surveys, that in most cases the intake of whole-grain is too low in adults (Cleveland et al. 2000, Thane et al. 2005) as well as in children and adolescents (Brady et al. 2000). Alexy et al. (2010) also reported a negative age trend of whole-grain intake. Therefore, it is important to prevent the risk that girls, aiming to reduce their weight, turn to self-made diets lacking in carbohydrates.

Further differences between sexes were observed regarding the perception of socio-cultural attributes of foods, and in particular of fashionability. Indeed, girls considered fattening foods (both overall and with reference to many specific food categories) as less fashionable when compared to their male counterparts. This may be due to higher exposure to advertisements showing fattening foods in a modern environment.

Finally, no association was revealed between the weight status and food perception. Therefore, despite the perception of foods affects the nutritional behavior and thus may contribute to deviations from the condition of normal weight, one individual's weight status is more directly determined by other organic or psychological factors.

\section{Conclusions}

In conclusion, this study provides important insights concerning the perception of fattening foods in the Northern Italian youth population. The present findings can serve for future research and potential nutritional interventions in children and adolescents. Further research should be carried out in other populations to identify how food perception is affected by cultural and social factors.

\section{Methods}

The sample consists of 549 subjects, attending the primary school (children, aged 8-11; F: 125, M: 119) and the middle school (adolescents, aged 11-14; F: 153; M: 152) in Bologna, Emilia-Romagna, Northern Italy. The participants were randomly selected, and interviewed in the school year 2008-2009. The school institutions involved provided their approval to conduct the study, 
and parental informed consent was obtained for each participant.

Body height and weight were measured and the BMI (weight in kilograms divided by height squared in centimetres) was computed. According to his/her BMI, each subject was classified as underweight, normal weight, overweight, or obese, using International Obesity Taskforce (2012) thresholds for sex and exact age. Underweight was determined using the thresholds of Cole et al. (2007).

An individual oral interview was conducted, in which each participant was asked to indicate through an open choice five foods having, according to the individual opinion, a fattening effect. Then, for each of the five indicated foods, a yes-no answer was required to the question "is this food special for you?", concerning the subject's appreciation of the food, and to six questions of the type "is this food ....?", concerning socio-cultural attributes of the food: new, fashionable, natural, local, typical of the city, typical of the countryside. The questions have been adapted from a questionnaire developed by Ulijaszek in a pilot study regarding the environmental factors contributing to obesity (2007).

All the foods indicated, according to similarities in their composition, nutritional characteristics, and pattern of consumption by children and adolescents, were grouped in 18 categories. Each category was named as the most representative food(s) of that category: biscuits and ice creams; bread and pasta; chocolate and snacks; cold cuts; dairy products; eggs; fat meat; filled cakes and sweets; fish; fried fish; fried potatoes; juices and drinks; lean meat; non-sweet fruit and cereals; oils and condiments; pizza; sweet fruit; vegetables.

Data are reported as percentage values. Pearson's Chisquare tests were used to assess the association between the examined categorical variables, namely age class, weight status, food category, appreciation and sociocultural attributes of the food. The statistical significance was set at $\mathrm{p}<0.05$. The analyses were carried out separately for boys and girls. All the analyses were carried out using the $\mathrm{R}$ statistical software ( $\mathrm{R}$ Development Core Team 2011).

\section{Competing interests}

The authors declare that they have no competing interests.

\section{Authors' contribution}

ST conceived the study, performed the acquisition and interpretation of data. PB has been involved in drafting the manuscript and revising it critically. RDM participated in the design of the study and performed the statistical analysis. FS drafted the manuscript and participated in its design and coordination. All authors read and approved the final manuscript.

Received: 26 June 2014 Accepted: 29 July 2014

Published: 4 August 2014

\section{References}

Aldridge V, Dovey TM, Halford JCG (2009) The role of familiarity in dietary development. Dev Rev 29:32-44
Alexy U, Zorn C, Kersting M (2010) Whole grain in children's diet: intake, food sources and trends. Eur J Clin Nutr 64:745-751

Argnani L, Toselli S, Gualdi-Russo E (2008) Body image and growth in Italy. Coll Antropol 32:413-418

Bannon K, Schwartz MB (2006) Impact of nutrition messages on children's food choice: pilot study. Appetite 46:124-129

Boukthir S, Essaddam L, Mazigh Mrad S, Ben Hassine L, Gannouni S, Nessib F, Bouaziz A, Brini I, Sammoud A, Bouyahia O, Zouari B (2011) Prevalence and risk factors of overweight and obesity in elementary schoolchildren in the metropolitan region of Tunis, Tunisia. Tunis Med 89:50-54

Boulton TJ, Magarey AM, Cockington RA (1995) Tracking of serum lipids and dietary energy, fat and calcium intake from 1 to 15 years. Acta Paediatr 84:1050-1055

Brady LM, Lindquist CH, Herd SL, Goran MI (2000) Comparison of children's dietary intake patterns with US dietary guidelines. Br J Nutr 84:361-367

Cacciari E, Milani S, Balsamo A, Spada E, Bona G, Cavallo L, Cerutti F, Gargantini L, Greggio N, Tonini G, Cicognani A (2006) Italian cross-sectional growth charts for height, weight and BMI (2 to $20 \mathrm{yr}$ ). J Endocrinol Invest 29:581-593

Cleveland LE, Moshfegh AJ, Albertson AM, Goldman JD (2000) Dietary intake of whole grains. J Am Coll Nutr 19:331S-3385

Cole TJ, Flegal KM, Nicholls D, Jackson AA (2007) Body mass index cut offs to define thinness in children and adolescents: international survey. BMJ 335:194

Cook JT, Frank DA (2007) Food security, poverty, and human development in the United States. Ann N Y Acad Sci 1136:193-209

Cornwell TB, McAlister AR (2011) Alternative thinking about starting points of obesity. Development of child taste preferences. Appetite 56:428-439

Demory-Luce D, Morales M, Nicklas T, Baranowski T, Zakeri I, Berenson G (2004) Changes in food group consumption patterns from childhood to young adulthood: the Bogalusa Heart Study. J Am Diet Assoc 104:1684-1691

Haerens L, Vereecken C, Maes L, De Bourdeaudhuij I (2010) Relationship of physical activity and dietary habits with body mass index in the transition from childhood to adolescence: a 4-year longitudinal study. Public Health Nutr 13:1722-1728

Halford JCG, Boyland EJ, Hughes G, Oliveira LP, Dovey TM (2007) Beyond brand effect of television (TV) food advertisement/commercials on caloric intake and food choice of 5-7 year old children. Appetite 49:263-276

Harris G (2008) Development of taste and food preferences in children. Curr Opin Clin Nutr Metab Care 11:315-319

Harrison K, Marske AL (2005) Nutritional content of foods advertised during the television programs children watch most. Am J Public Health 95:1568-1574

Inran (2009) Zoom8-Studio di approfondimento sulle abitudini alimentari e lo stile di vita dei bambini delle scuole primarie. [Deepening study on the nutritional habits and lifestyle of primary school children]. http://nut. entecra.it/files/download/Pubblicazioni_divulgative/zoom8_2010.pdf. Accessed 20 April 2014

International Obesity Taskforce (2012) Global prevalence of adult obesity., http://www.worldobesity.org/site_media/uploads/Global_prevalence_of_ adult_obesity_Ranking_by_country_2012.pdf. Accessed 20 April 2014

Kaline K, Bornstein SR, Bergmann A, Hauner H, Schwarz PE (2007) The importance and effect of dietary fiber in diabetes prevention with particular consideration of whole grain products. Horm Metab Res 39:687-693

Kelly B, Halford JC, Boyland EJ, Chapman K, Bautista-Castaño I, Berg C, Caroli M, Cook B, Coutinho JG, Effertz T, Grammatikaki E, Keller K, Leung R, Manios Y, Monteiro R, Pedley C, Prell H, Raine K, Recine E, Serra-Majem L, Singh S, Summerbell C (2010) Television food advertising to children: a global perspective. Am J Public Health 100:1730-1736

Kranz S, Siega-Riz AM, Herring AH (2004) Changes in diet quality of American preschoolers between 1977 and 1998. Am J Public Health 94:1525-1530

Lake AA, Mathers JC, Rugg-Gunn AJ, Adamson AJ (2006) Longitudinal change in food habits between adolescence (11-12 years) and adulthood (32-33 years): the ASH30 Study. J Public Health 28:10-16

Lytle LA, Seifert S, Greenstein J, McGovern P (2000) How do children's eating patterns and food choices change over time? Results from a cohort study. Am J Health Promot 14:222-228

Marlett JA, McBurney MI, Slavin JL (2002) Position of the American Dietetic Association: health implication of dietary fiber. J Am Diet Assoc 102:993-1000

Mellen PB, Walsh TF, Herrington DM (2008) Whole grain intake and cardiovascular disease: a meta-analysis. Nutr Metab Cardiovasc Dis 18:283-290 
Nicklas TA, Webber LS, Berenson GS (1991) Studies of consistency of dietary intake during the first four years of life in a prospective analysis: Bogalusa Heart Study. J Am Coll Nutr 10:234-241

Noble C, Corney M, Eves A, Kipps M, Lumbers M (2000) Food choice and school meals: primary schoolchildren's perceptions of the healthiness of foods and the nutritional implications of foods choices. Int J Hosp Manag 19:413-432

R Development Core Team (2011) R: A language and environment for statistical computing. R Foundation for Statistical Computing, Vienna, Austria, URL http://www.r-project.org. ISBN ISBN 3-900051-07-0

Scully M, Wakefield M, Niven P, Chapman K, Crawford D, Pratt IS, Baur LA, Flood V, Morley B, NaSSDA Study Team (2012) Association between food marketing exposure and adolescents' food choices and eating behaviors. Appetite $58: 1-5$

Thane CW, Jones AR, Stephen AM, Seal CJ, Jebb SA (2005) Whole-grain intake of British young people aged 4-18 years. Br J Nutr 94:825-831

Toselli S, Argnani L, Canducci E, Ricci E, Gualdi-Russo E (2010) Food habits and nutritional status of adolescents in Emilia-Romagna, Italy. Nutr Hosp 25:613-621

Toselli S, Ventrella AR, Brasili P (2012) Prevalence and tracking of weight disorders in Italian primary school students: a three-year follow up. Coll Antropol 36:63-67

Toselli S, Brasili P, Iuliano T, Spiga F (2014) Anthropometric variables, lifestyle and sports in school-age children: comparison between the cities of Bologna and Crotone. Homo, in press

Ulijaszek SJ (2007) Frameworks of population obesity and the use of cultural consensus modeling in the study of environments contributing to obesity. Econ Hum Biol 5:443-457

World Health Organization (2009) Prevalence of overweight and obesity in children and adolescents., http://www.euro.who.int/_data/assets/pdf_file/ 0005/96980/2.3.-Prevalence-of-overweight-and-obesity-EDITED_layouted_V3.pdf. Accessed 20 April 2014

Yoon J, Lyu E, Lee K (2008) Korean adolescents' perceptions of nutrition and health towards fast foods in Busan area. Nutr Res Pract 2:171-177

doi:10.1186/2193-1801-3-402

Cite this article as: Toselli et al:: Perception of fattening foods in Italian children and adolescents. SpringerPlus 2014 3:402.

\section{Submit your manuscript to a SpringerOpen ${ }^{\circ}$ journal and benefit from:}

- Convenient online submission

- Rigorous peer review

- Immediate publication on acceptance

- Open access: articles freely available online

- High visibility within the field

- Retaining the copyright to your article

Submit your next manuscript at $>$ springeropen.com 